\title{
Activation of Large Conductance, Calcium-Activated Potassium Channels by Nitric Oxide Mediates Apelin-Induced Relaxation of Isolated Rat Coronary Arteries $\mathbf{S}$
}

\author{
Amreen Mughal, Chengwen Sun, and Stephen T. O'Rourke \\ Department of Pharmaceutical Sciences, North Dakota State University, Fargo, North Dakota \\ Received February 21, 2018; accepted May 15, 2018
}

\begin{abstract}
Apelin increases coronary blood flow, cardiac contractility, and cardiac output. Based on these favorable hemodynamic effects, apelin and apelin-like analogs are being developed for treating heart failure and related disorders; however, the molecular mechanisms underlying apelin-induced coronary vasodilation are unknown. This study aimed to elucidate the signaling pathways by which apelin causes smooth muscle relaxation in coronary arteries. Receptors for apelin (APJ receptors) were expressed in coronary arteries, as determined by Western blot and polymerase chain reaction analyses. Immunofluorescence imaging studies identified APJ receptors on endothelial and smooth muscle cells. In isolated endothelial cells, apelin caused an increase in 4,5-diaminofluorescein fluorescence that was abolished by nitro-L-arginine (NLA) and F13A (H-Gln-Arg-Pro-Arg-Leu-Ser-His-Lys-Gly-Pro-Met-ProAla-OH), an APJ receptor antagonist, consistent with increased nitric oxide (NO) production. In arterial rings, apelin caused
\end{abstract}

endothelium-dependent relaxations that were abolished by NLA, F13A, and iberiotoxin. Neither oxadiazolo[4,3-a]quinoxalin-1-one (ODQ) nor DT-2, a protein kinase G inhibitor, had any effect on apelin-induced relaxations, and apelin itself had no effect on intracellular cGMP accumulation in coronary arteries. Patchclamp studies in isolated smooth muscle cells demonstrated that the NO donors, diethyl amine NONOate and sodium nitroprusside, caused increases in large conductance, calcium-activated potassium channel $\left(\mathrm{BK}_{\mathrm{Ca}}\right)$ currents, which were inhibited by iberiotoxin but not ODQ. Thus, apelin causes endothelium-dependent relaxation of coronary arteries by stimulating endothelial APJ receptors and releasing NO, which acts in a cGMP-independent manner and increases $\mathrm{BK}_{\mathrm{Ca}}$ activity in the underlying smooth muscle cells. These results provide a mechanistic basis for apelin-induced coronary vasodilation and may provide guidance for the future development of novel apelin-like therapeutic agents.

\section{Introduction}

The vasoactive peptide, apelin, was initially discovered as the endogenous ligand for the $\mathrm{G}$ protein-coupled apelin receptor known as APJ (Tatemoto et al., 1998). A growing body of evidence indicates that apelin has diverse physiologic effects, including regulation of cardiovascular function (O'Carroll et al., 2013). Apelin and APJ receptors are widely expressed in the cardiovascular system, including the heart (Kleinz and Davenport, 2004), blood vessels (Kleinz et al., 2005; Pitkin et al., 2010), and cardiovascular regulatory centers in the brain (Hosoya et al., 2000; Reaux et al., 2002; Zhang et al., 2009). Apelin is also formed in adipocytes, where it may be released into the bloodstream and serve as an adipokine (Boucher et al., 2005). As such, the role of apelin in various cardiovascular disorders is of considerable interest.

This work was supported by the National Institutes of Health National Heart, Lung, and Blood Institute [Grant R15 HL124338]

https://doi.org/10.1124/jpet.118.248682.

S This article has supplemental material available at jpet.aspetjournals.org.
Apelin/APJ signaling has significant effects on vascular tone. In rodent models, apelin causes a marked reduction in arterial blood pressure that is attenuated by pharmacologic inhibition with F13A (H-Gln-Arg-Pro-Arg-Leu-Ser-His-LysGly-Pro-Met-Pro-Ala-OH), an APJ receptor antagonist (Lee et al., 2005), or by deletion of the APJ receptor gene (Ishida et al., 2004). In humans, systemic administration of apelin lowers mean arterial blood pressure and reduces peripheral vascular resistance (Japp et al., 2010; Barnes et al., 2013), effects that are consistent with arterial vasodilation. Studies in isolated blood vessels indicate that apelin has complex effects on vascular function. Apelin causes relaxation of vascular smooth muscle via both endothelium-dependent and endothelium-independent mechanisms, depending on the origin of the blood vessel (Gurzu et al., 2006; Salcedo et al., 2007; Maguire et al., 2009; Wang et al., 2015). Apelin may also cause contractions in isolated vessels in which the endothelium has been damaged or removed (Maguire et al., 2009; Han et al., 2013).

Based on the favorable hemodynamic profile of apelin, there is increasing interest in the apelin/APJ signaling system as a

ABBREVIATIONS: 5-HT, 5-hydroxytryptamine; APJ, apelin receptor; BCA, bicinchoninic acid; $\mathrm{BK}_{\mathrm{Ca}}$ channel, large conductance calcium-activated potassium channel; CPA, cyclopiazonic acid; DAF-2, diaminofluorescein; DEA, diethyl amine; eNOS, endothelial nitric oxide synthase; F13A, H-GlnArg-Pro-Arg-Leu-Ser-His-Lys-Gly-Pro-Met-Pro-Ala-OH; L-NAME, N-nitro-L-arginine methyl ester; NLA, nitro-L-arginine; NO, nitric oxide; ODQ, oxadiazolo[4,3-a]quinoxalin-1-one; PECAM, platelet endothelial cell adhesion molecule; PKG, protein kinase G; SERCA, sarcoplasmic reticulum ATPase; SNP, sodium nitroprusside. 
potential target for developing novel therapeutic strategies to treat disorders such as heart failure and pulmonary arterial hypertension (Brame et al., 2015; Narayanan et al., 2015; Yang et al., 2015). In the heart, apelin increases coronary blood flow, cardiac contractility, and cardiac output, and these effects of apelin are preserved in patients with heart failure (Japp et al., 2010; Barnes et al., 2013). At present, the molecular mechanisms underlying apelin-induced coronary vasodilation are unknown, thus limiting our understanding of the vascular actions of apelin under both physiologic and pathophysiological conditions. Hence, this study was designed to elucidate the signaling pathways by which apelin causes smooth muscle relaxation in coronary arteries.

\section{Materials and Methods}

Animals and Tissue Preparation. Experiments were performed on tissues isolated from 12-week-old male Sprague-Dawley rats (Envigo RMS, Indianapolis, IN). Rats were kept on a 12-hour/12-hour light/dark cycle at $22 \pm 2^{\circ} \mathrm{C}$ and food and water were provided ad libitum. The North Dakota State University Institutional Animal Care and Use Committee approved the animal protocols used in this study. Hearts were isolated from animals anesthetized with isoflurane and placed into ice-cold physiologic salt solution of the following composition: $118.9 \mathrm{mM} \mathrm{NaCl}, 4.7 \mathrm{mM} \mathrm{KCl}, 2.5 \mathrm{mM} \mathrm{CaCl}_{2}, 1.2 \mathrm{mM}$ $\mathrm{MgSO}_{4} .7 \mathrm{H}_{2} \mathrm{O}, 1.2 \mathrm{mM} \mathrm{KH}_{2} \mathrm{PO}_{4}, 25.0 \mathrm{mM} \mathrm{NaHCO} 3,5.5 \mathrm{mM}$ glucose, and $0.03 \mathrm{mM}$ EDTA. Epicardial coronary arteries were dissected and cleaned of surrounding tissues.

Western Immunoblotting. Coronary arteries were isolated and immediately frozen in liquid nitrogen. APJ receptor protein was detected according to our previously published method for coronary arteries, with minor modifications (Tunstall et al., 2011). The blots were incubated with a primary antibody specific for APJ receptors (Santa Cruz Biotechnology Inc., Dallas, TX), which was used at a dilution of 1:200, and $\beta$-actin expression was measured as a loading control. The blots were first probed with APJ receptor antibody, followed by chemical stripping and reprobing with $\beta$-actin antibody (Santa Cruz). An enhanced chemiluminescence light detection kit (Thermo Fisher Scientific, Waltham, MA) was used for immunodetection.

Real-Time Quantitative Polymerase Chain Reaction. Freshly isolated tissues were frozen immediately in liquid nitrogen and total RNA was isolated with the use of an RNeasy Mini Kit, according to the manufacturer's protocol (Qiagen, Germantown, MD). A spectrophotometer (Nanodrop Technologies, Wilmington, DE) was used to determine the concentration and purity of RNA. The cDNA was synthesized from $50 \mathrm{ng}$ RNA and the use of an iScript cDNA synthesis kit (Bio-Rad, Hercules, CA). A SYBR Green expression assay was used to determine expression of APJ receptors, with $\beta$-actin used as a housekeeping gene (Bio-Rad). The following primers (synthesized by Invitrogen, Carlsbad, CA) were used: 5'-ACAAGACATGTGCCATTGGA-3' (forward) and 5'-TCTCCCAGAAGCCTCCTACA-3' (reverse) for the APJ receptor and 5'-GTCGTACCACTGGCATTGTG-3' (forward) and 5'-TCTCAGCTGTGGTGGTGAAG-3' (reverse) for $\beta$-actin. The reaction conditions were set at $95^{\circ} \mathrm{C}$ for 10 minutes, followed by 40 cycles of $95^{\circ} \mathrm{C}$ for 10 seconds, $60^{\circ} \mathrm{C}$ for 20 seconds, and $72^{\circ} \mathrm{C}$ for 30 seconds.

Immunofluorescence Microscopy. Freshly isolated coronary arteries were fixed in formalin solution (10\%), processed, and embedded in paraffin. Tissue sections $(5 \mu \mathrm{m})$ were prepared from paraffin blocks, mounted onto microscopic slides (ProbeOn Plus; Thermo Fisher Scientific), and fixed by heating at $60^{\circ} \mathrm{C}$ for 30 minutes. Nonspecific binding of antibodies was blocked by incubation with normal serum [10\% (w/v); in Tris-buffered saline] for 1 hour at room temperature. Sections were incubated at $4^{\circ} \mathrm{C}$ overnight in $1 \%$ serum containing primary antibodies against APJ receptors (Abcam,
Cambridge, MA), smooth muscle actin (Santa Cruz Biotechnology), and/or platelet endothelial cell adhesion molecule (PECAM)-1 (Santa Cruz Biotechnology). For colocalization studies, double immunofluorescent staining was accomplished by simultaneously incubating the tissue sections with more than one primary antibody. Primary antibodies against the APJ receptor, smooth muscle actin, and PECAM-1 were detected by using Texas red-conjugated (goat antirabbit IgG; Invitrogen), Alexa Fluor 488 (goat anti-mouse IgG; Santa Cruz Biotechnology), and Alexa Fluor 555 (donkey anti-goat IgG; Santa Cruz Biotechnology) secondary antibodies, respectively. Negative controls were incubated with $1 \%$ serum solution overnight followed by secondary antibodies. Tris-buffered saline containing Triton X-100 [0.3\% (v/v)] was used for all dilutions and thorough washes between stages, unless otherwise stated. Sections were blotted with filter paper, and a drop of mounting medium containing an antifade reagent (Vector Laboratories, Burlingame, CA) was placed on each slide. Tissue sections were imaged with an Olympus confocal laser-scanning microscope (Olympus, Tokyo, Japan) and Olympus FluoView FV300 (version 4.3) confocal software was used to generate the images.

Vascular Function Studies. Arterial rings (120-150 $\mu \mathrm{m} ; 1.2 \mathrm{~mm}$ in length) were placed in wire myographs (DMT, Aarhus, Denmark) for recording isometric tension. The myograph chambers were filled with physiologic salt solution $(5 \mathrm{ml})$, which was aerated continuously with $95 \% \mathrm{O}_{2} / 5 \% \mathrm{CO}_{2}$ and maintained at $37^{\circ} \mathrm{C}$ throughout the experiment. The vessels were stretched to a resting tension of $7.5 \mathrm{mN}$ and then allowed to stabilize for 30-40 minutes with intermittent washings. Vessel reactivity was confirmed by evoking a contractile response to $\mathrm{KCl}$ $(60 \mathrm{mM})$. In some vessels, the endothelial cells were removed by gently rubbing the intimal surface with a human hair. The presence or absence of endothelium was confirmed by measuring relaxation in response to the endothelium-dependent vasodilator, acetylcholine $\left(10^{-6} \mathrm{M}\right)$. Responses to the vasodilators used in this study were obtained in arterial rings contracted with 5-hydroxytryptamine (5-HT) $\left(10^{-7} \mathrm{M}\right)$, a potent coronary vasoconstrictor that is released from aggregating platelets and has been linked to increased vasomotor tone in the setting of coronary artery disease (Houston et al., 1986; Golino et al., 1994; Kleinbongard et al., 2011; Li et al., 2012), unless otherwise stated. Inhibitors were added to the myograph chamber 20 minutes prior to contraction with 5 -HT and they remained in contact with the tissues for the remainder of the experiment. Experiments with inhibitors were conducted in parallel with control rings taken from the same animal.

Coronary Endothelial Cell Isolation. Endothelial cells were isolated from coronary arteries as previously described (Sonkusare et al., 2012) with minor modifications. Briefly, coronary arteries were digested in dissociation solution $(55 \mathrm{mM} \mathrm{NaCl}, 80 \mathrm{mM}$ Na-glutamate, $6 \mathrm{mM} \mathrm{KCl}, 2 \mathrm{mM} \mathrm{MgCl}_{2}, 0.1 \mathrm{mM} \mathrm{CaCl}_{2}, 10 \mathrm{mM}$ glucose, and $10 \mathrm{mM}$ HEPES, $\mathrm{pH} 7.3)$ containing neutral protease $(0.5 \mathrm{mg} / \mathrm{ml})$ (Worthington, Lakewood, $\mathrm{NJ}$ ) and elastase $(0.5 \mathrm{mg} / \mathrm{ml}$ ) (Worthington) for 60 minutes at $37^{\circ} \mathrm{C}$. Collagenase (Worthington type II, $0.5 \mathrm{mg} / \mathrm{ml}$ ) was then added to the same enzyme solution and digestion was continued for 2 minutes. The artery was removed and placed back in the dissociation solution without enzymes for an additional 10 minutes before trituration with a polished Pasteur pipette to produce a suspension of single endothelial cells.

Real-Time NO Imaging. Freshly isolated endothelial cells were allowed to attach in eight-well LabTek chambers (Thermo Fisher Scientific) for 3 to 4 hours. The cells were then loaded with the $\mathrm{NO}$-sensitive fluorescent dye, 4,5-diaminofluorescein (DAF-2) diacetate (Thermo Fisher Scientific; $5 \mu \mathrm{M} ; 60$ minutes at room temperature). Real-time imaging was performed using an Olympus confocal laser-scanning microscope with a $40 \times$ numerical aperture oil immersion lens (with excitation at $488 \mathrm{~nm}$ and emission at $515 \mathrm{~nm}$ ). All experiments were carried out at room temperature in Hank's balanced salt solution. The effects of agonists and inhibitors on intracellular NO levels were obtained in paired experiments. In experiments with NLA $\left(3 \times 10^{-5} \mathrm{M}\right)$ and F13A $\left(10^{-7} \mathrm{M}\right)$, the inhibitors were added to the chamber for 10 minutes before addition of apelin $\left(10^{-7} \mathrm{M}\right)$. After 
DAF-2 imaging, cells were washed and fixed with ice-cold ethanol and stained with PECAM-1 and smooth muscle cell actin antibodies. Immunofluorescence imaging showed positive staining for PECAM-1, but not for smooth muscle cell actin. Endothelial cells were isolated from 4 to 6 animals (each animal on a different day) and 2 to 3 cells were analyzed for each treatment from each animal.

cGMP Estimation. Coronary arterial cGMP levels were determined by ELISA, according to our previously described method (Tunstall et al., 2011). Arterial segments were treated with apelin $\left(10^{-7}\right.$ and $10^{-6} \mathrm{M}, 5$ minutes) or acetylcholine (ACh; $10^{-6} \mathrm{M}$, 5 minutes). In some experiments, the tissues were incubated with NLA $\left(3 \times 10^{-5} \mathrm{M}\right)$ or ODQ $\left(10^{-5} \mathrm{M}\right)$ for 20 minutes before being exposed to apelin or acetylcholine. Tissue cGMP levels are expressed as picomoles per microgram of protein.

Coronary Smooth Muscle Cell Isolation. Vascular smooth muscle cells were isolated as described previously, with minor modification (Gonzales et al., 2010). Arteries were put into a cell isolation solution of the following composition: $60 \mathrm{mM} \mathrm{NaCl}, 80 \mathrm{mM}$ Na-glutamate, $5 \mathrm{mM}$ $\mathrm{KCl}, 2 \mathrm{mM} \mathrm{MgCl}$, $10 \mathrm{mM}$ glucose, and $10 \mathrm{mM}$ HEPES, $\mathrm{pH}$ 7.2. Arterial segments were digested initially with $1.2 \mathrm{mg} / \mathrm{ml}$ papain (Worthington) and $2.0 \mathrm{mg} / \mathrm{ml}$ dithioerythritol (Sigma Aldrich, St. Louis, MO) for 17 minutes, followed by $0.8 \mathrm{mg} / \mathrm{ml}$ type II collagenase (Worthington) for 12 minutes. All incubations were performed at $37^{\circ} \mathrm{C}$. After digestion, the arterial segments were placed in fresh ice-cold isolation solution for 30 minutes and then triturated with a polished Pasteur pipette to yield a suspension of single smooth muscle cells. Isolated smooth muscle cells were used for electrophysiological recordings within 6 hours.

Electrophysiological Recording. Isolated smooth muscle cells were put into a recording chamber (Warner Instruments, Hamden, CT) at room temperature and superfused at a rate of $2.0 \mathrm{ml} / \mathrm{min}$ with a solution containing $145 \mathrm{mM} \mathrm{NaCl}, 5.4 \mathrm{mM} \mathrm{KCl}, 1.8 \mathrm{mM} \mathrm{CaCl}_{2}, 1 \mathrm{mM} \mathrm{MgCl}_{2}$, $5 \mathrm{mM}$ HEPES, and $10 \mathrm{mM}$ glucose, $\mathrm{pH} 7.4(\mathrm{NaOH})$. Patch pipettes were filled with internal pipette solution containing $145 \mathrm{mM} \mathrm{KCl}, 5 \mathrm{mM} \mathrm{NaCl}$,
$0.37 \mathrm{mM} \mathrm{CaCl}_{2}, 2 \mathrm{mM} \mathrm{MgCl}_{2}, 10 \mathrm{mM}$ HEPES, $1 \mathrm{mM} \mathrm{EGTA}$, and $7.5 \mathrm{mM}$ glucose, $\mathrm{pH} 7.2(\mathrm{KOH})$. The estimated free $\mathrm{Ca}^{2+}$ concentration in the pipette solution was $\left[10^{-7} \mathrm{M}\right]$. Whole cell $\mathrm{K}$ currents were recorded with the use of an AxoPatch 200B amplifier outfitted with an Axon CV 203BU headstage (Molecular Devices, Sunnyvale, CA), as described previously (Modgil et al., 2013). Current data were collected and analyzed with pCLAMP 10.0 software (Molecular Devices). The patch electrodes (3 to $4 \mathrm{M} \Omega$ ) were fashioned from $1.5-\mathrm{mm}$ borosilicate glass capillaries. All drugs were diluted in fresh bath solution and perfused into the experimental chamber. Standard recording conditions for $\mathrm{BK}_{\mathrm{Ca}}$ currents were achieved by stepping in $10-\mathrm{mV}$ increments from a holding potential of -60 to $+80 \mathrm{mV}$. $\mathrm{BK}_{\mathrm{Ca}}$ currents were expressed as current density (current divided by cell membrane capacitance).

Drugs. The following drugs were used: acetylcholine, diethyl amine (DEA) NONOate, sodium nitroprusside (SNP), diltiazem, 5-HT, indomethacin, DT-2 trifluoroacetate salt, nitro-L-arginine (NLA), and glyburide (Sigma Chemical, St. Louis, MO); iberiotoxin and $1 \mathrm{H}-[1,2,4]$ oxadiazolo[4,3-a] quinoxalin-1-one (ODQ) (Tocris, Ellisville, MO); apelin13 and F13A trifluoro-acetate salt (Bachem, Torrance, CA); and cyclopiazonic acid (CPA) (Abcam). Drug solutions were prepared fresh daily, protected from light, and kept on ice until used. All drugs were dissolved in double-distilled water, with the exception of ODQ and CPA (which were dissolved initially in dimethylsulfoxide), indomethacin (which was dissolved initially in $1 \mathrm{mM}$ sodium carbonate), and glyburide (which was dissolved initially in $0.1 \mathrm{~N} \mathrm{NaOH}$ prior to further dilution in doubledistilled water). Drugs were added to the myograph chambers in volumes not greater than $0.02 \mathrm{ml}$. Drug concentrations are reported as final molar concentrations in the myograph chamber.

Data Analysis. Relaxation responses are expressed as a percent of the initial tension induced by $5-\mathrm{HT}\left(10^{-7} \mathrm{M}\right) . \mathrm{EC}_{50}$ values were calculated by interpolating from each curve the concentration of agonist producing a relaxation halfway between the level of the preexisting contraction and the maximal relaxation obtained with that agonist,
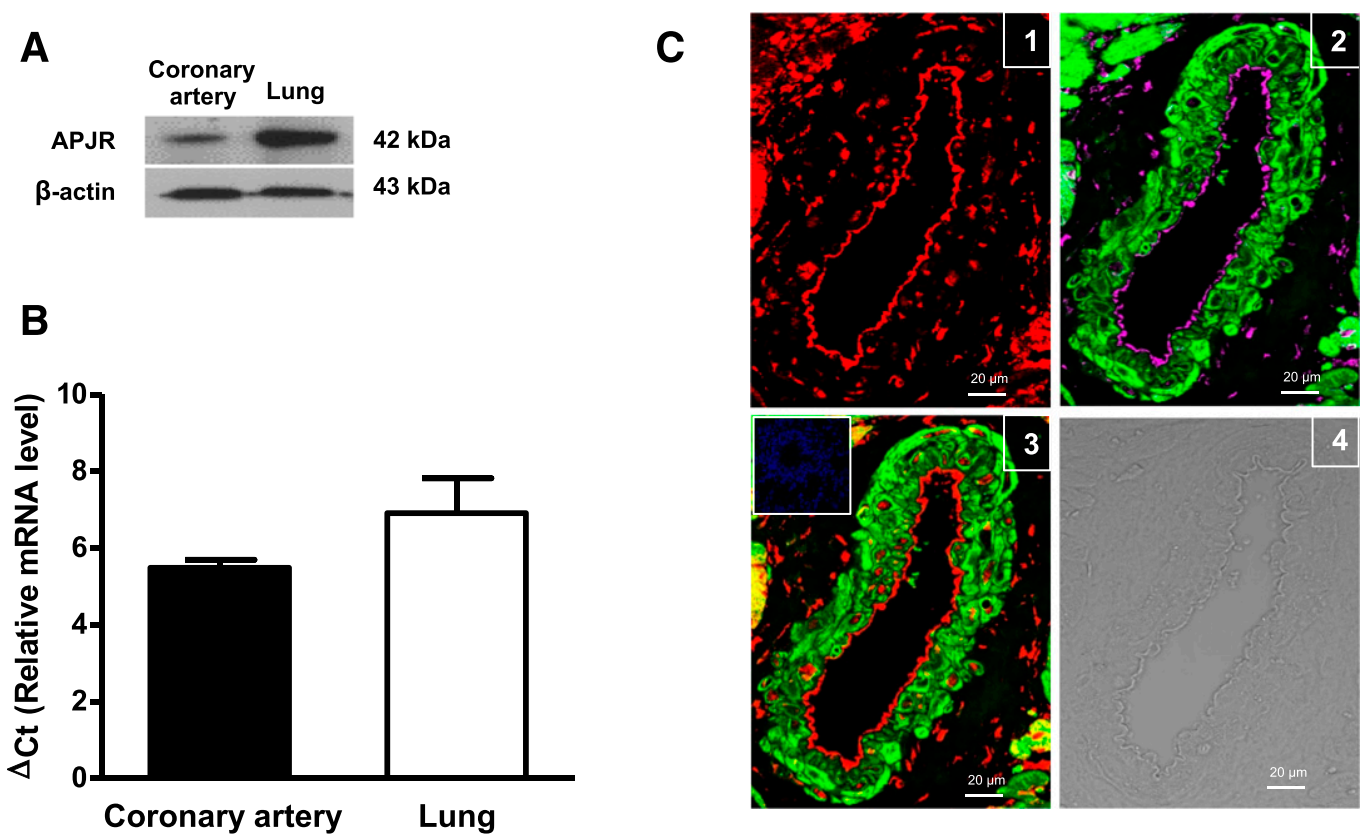

Fig. 1. Expression and localization of APJ receptors in coronary arteries. (A) Representative immunoblot showing expression of APJ receptor protein in homogenates from rat coronary arteries (lane 1) and lung tissue (lane 2); $\beta$-actin was used as a loading control. The immunoblots shown are representative of data obtained from five different animals. (B) Bar graph showing relative mRNA expression of APJ receptor, represented as $\Delta$ Ct values relative to $\beta$-actin. Data are presented as the mean \pm S.E.M. $(n=3)$. (C) Representative immunofluorescence images of (1) APJ receptors (red fluorescence), (2) a merged image showing PECAM-1 in endothelial cells (magenta fluorescence) and actin in smooth muscle cells (green fluorescence), (3) a merged image showing APJ receptor colocalized areas in smooth muscle cells (yellow fluorescence) and endothelium (red fluorescence) in rat coronary artery [the inset demonstrates a lack of staining after incubation of tissue with serum followed by the secondary antibody (negative control)], and (4) a differential interference contrast image of rat coronary artery. The images are representative of those obtained from three different animals. Scale bar, $20 \mu \mathrm{m}$. APJR, APJ receptor; $\Delta \mathrm{Ct}$, delta threshold cycle. 


\section{A}

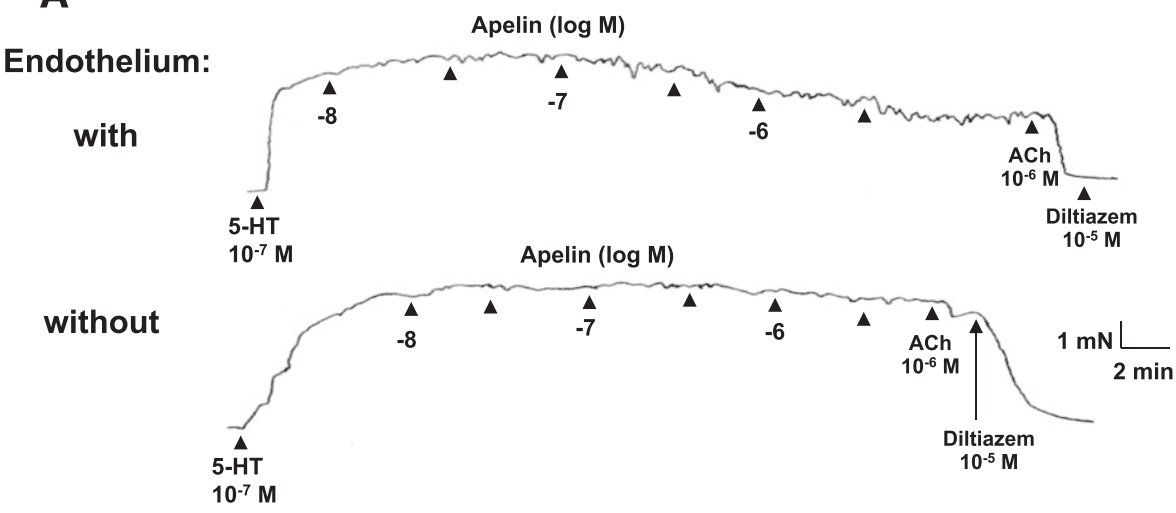

B

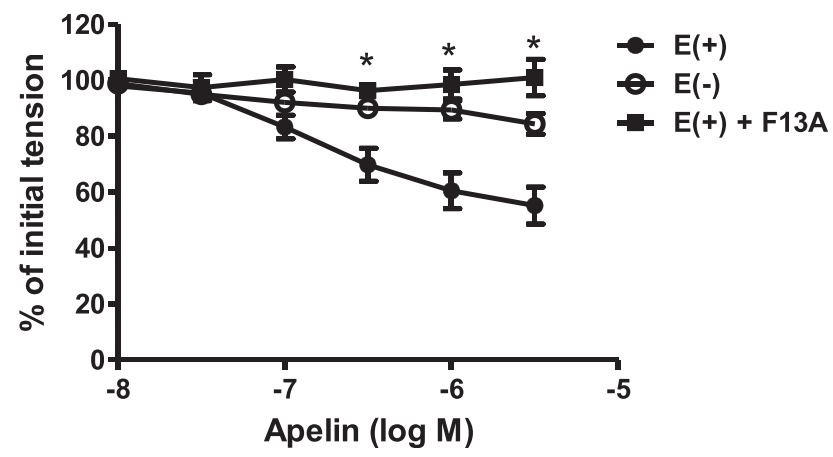

Fig. 2. Effect of endothelium removal and APJ receptor antagonism on apelin-induced relaxation of isolated rat coronary arteries. (A) Representative original tracings of isometric tension recordings from rat isolated coronary arteries (with and without endothelium) in response to cumulative addition of increasing concentrations of apelin, followed by acetylcholine $\left(10^{-6} \mathrm{M}\right)$ and diltiazem $\left(10^{-5} \mathrm{M}\right)$. (B) Mean data demonstrating apelin-induced relaxation in coronary arteries with endothelium (E+), which was abolished in the endothelium denuded $(\mathrm{E}-)$ segments or in the presence of F13A $\left(10^{-7} \mathrm{M}\right)$. Data are expressed as a percentage of the initial increase in tension induced by 5-HT $\left(10^{-7} \mathrm{M}\right)$. Each point represents the mean \pm S.E.M. $(n=$ $5-9)$. $* P<0.05$ vs. E+ as calculated by analysis of variance using the Tukey test as post hoc analysis. ACh, acetylcholine. converted to their negative logarithms, and expressed as the - log molar $\mathrm{EC}_{50}\left(\mathrm{pD}_{2}\right)$ value. Real-time quantitative polymerase chain reaction data were analyzed to quantify relative gene expression by delta threshold cycle relative to $\beta$-actin. For nitric oxide (NO) imaging, amplitude of DAF-2 fluorescence was calculated by subtracting peak fluorescence intensity from basal fluorescence intensity. Results are expressed as means \pm S.E.M., and $n$ indicates the number of animals from which blood vessels were collected, unless otherwise stated. Values were compared by the $t$ test or one-way analysis of variance using the Tukey test as post hoc analysis for paired or unpaired observations, as appropriate, to determine significance between groups. Values were considered to differ significantly when $P<0.05$.

\section{Results}

Receptors for Apelin Are Expressed in Coronary Arteries. Expression of APJ receptor protein was demonstrated in rat coronary arteries by Western immunoblot analysis. A strong immunoreactive band associated with APJ receptors was observed at $42 \mathrm{kDa}$ in homogenates from the rat coronary artery and lung, which was used as a positive control (Fig. 1A) (Hosoya et al., 2000). Expression of mRNA transcripts in rat coronary arteries was confirmed by real-time quantitative polymerase chain reaction (Fig. 1B). In imaging studies using immunofluorescence and confocal microscopy, APJ receptor protein was detected in rat coronary arteries (Fig. 1C1), where it was localized to the endothelial and smooth muscle cell layers. Smooth muscle cell actin was detected in the smooth muscle cell layer and PECAM-1 was observed in the endothelial layer (Fig. 1C2). Although some APJ receptors colocalized with actin in the smooth muscle cell layer, staining for APJ receptors was more uniform in the endothelium (Fig. 1C3).
Apelin Causes Endothelium-Dependent Relaxation of Coronary Arteries. Apelin $\left(10^{-8}-3 \times 10^{-6} \mathrm{M}\right)$ caused concentration-dependent relaxation of isolated rat coronary arteries with intact endothelium (Fig. 2). The $\mathrm{pD}_{2}$ value for apelin was $6.90 \pm 0.12$ and the maximal relaxation was $45 \% \pm$ $6 \%$. By comparison, the prototypical endothelium-dependent vasodilator, acetylcholine, was similar in potency $\left(\mathrm{pD}_{2}=6.89\right.$ $\pm 0.12)$ but was more effective $\left(E_{\max }: 97 \% \pm 1 \%\right.$ relaxation; $P<0.05 ; n=8)$ than apelin in producing relaxation. The relaxation response to apelin was essentially abolished by removal of the endothelium or by inhibition of APJ receptors with F13A $\left(10^{-7} \mathrm{M}\right)$ (Fig. 2B). These same concentrations of apelin had no measurable effect on vascular tone in quiescent coronary arterial rings under resting conditions.

Inhibition of prostaglandin synthesis with indomethacin $\left(10^{-5} \mathrm{M}\right)$ had no effect on the concentration-response curve to apelin $\left(\mathrm{pD}_{2}=6.89 \pm 0.1\right.$ vs. $7.01 \pm 0.2 ; E_{\max }=39 \% \pm 4 \%$ vs. $36 \% \pm 8 \%$; in the absence and presence of indomethacin, respectively; $P>0.05, n=8$ ), whereas the nitric oxide synthase inhibitor, NLA $\left(3 \times 10^{-5} \mathrm{M}\right)$, completely inhibited the response to apelin (Fig. 3A). In freshly isolated endothelial cells, apelin $\left(10^{-7} \mathrm{M}\right)$ caused an increase in DAF-2 fluorescence consistent with the formation of intracellular nitric oxide (Fig. 3B). The apelin-induced increase in DAF-2 fluorescence was inhibited by NLA $\left(3 \times 10^{-5} \mathrm{M}\right)$ and by F13A $\left(10^{-7} \mathrm{M}\right)$ (Fig. 3C). Neither NLA nor F13A had any effects of their own on DAF-2 fluorescence.

Inhibitors of Guanylyl Cyclase, Protein Kinase G, and Sarcoplasmic Reticulum ATPase Have No Effect on Apelin-Induced Relaxation. Relaxations induced by apelin were insensitive to inhibition of soluble guanylyl cyclase with 
A

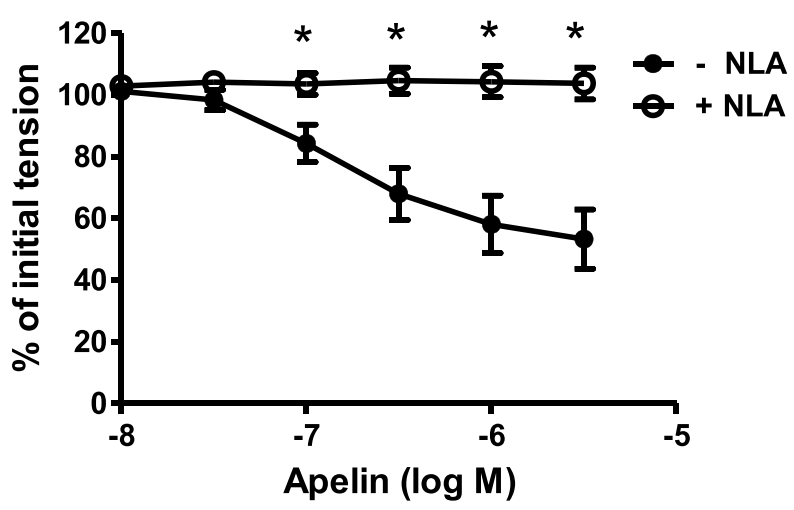

B
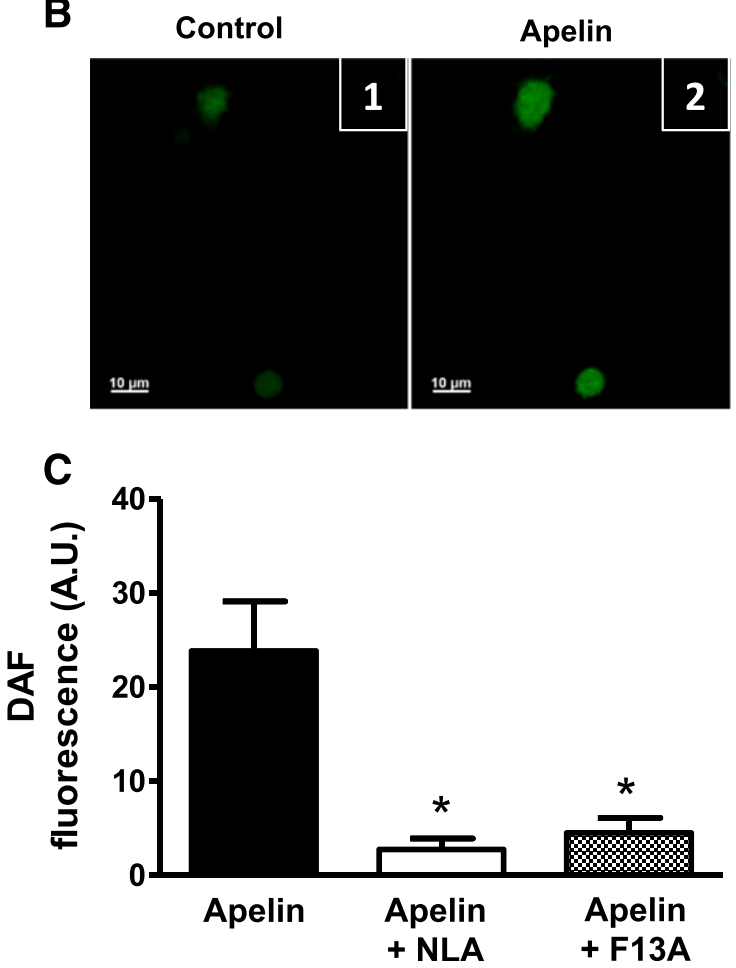

Fig. 3. Role of NO in apelin-induced relaxation of coronary arteries. (A) Log concentration-response curve for apelin in producing relaxation of endothelium-intact coronary arteries in the absence and presence of NLA $\left(3 \times 10^{-5}\right.$ $\mathrm{M}, n=6$ ). (B) Representative images of freshly isolated coronary endothelial cells loaded with DAF-2 (5 $\mu \mathrm{M})$ (1) before and (2) after exposure to apelin $\left(10^{-7} \mathrm{M}\right)$. (C) Bar graph representing increase in DAF-2 fluorescence after exposure to apelin $\left(10^{-7} \mathrm{M}\right)$ in the absence and presence of NLA $\left(3 \times 10^{-5} \mathrm{M}\right)$ or F13A $\left(10^{-7} \mathrm{M}\right)$. Amplitude of change in DAF-2 fluorescence was calculated as the maximal fluorescence after agonist exposure, corrected for baseline fluorescence. Values are represented as the mean \pm S.E.M. $(n=$ $4-6)$. $* P<0.05$ vs. apelin alone as calculated by analysis of variance using the Tukey test as post hoc analysis. A.U., arbitrary unit.

ODQ $\left(10^{-5} \mathrm{M}\right)$ and to inhibition of protein kinase $\mathrm{G}$ (PKG) with DT-2 (10 $\left.{ }^{-6} \mathrm{M}\right)$ (Fig. 4, A and B). Moreover, exposure of freshly isolated coronary arteries to apelin had no effect on intracellular cGMP levels either in the absence (Fig. 5A) or presence (Supplemental Fig. 1) of 5-HT. By comparison, acetylcholineinduced relaxations were impaired by both ODQ and DT-2 (Fig. 4, C and D), and acetylcholine caused a significant increase in intracellular cGMP that was inhibited by NLA $\left(3 \times 10^{-5} \mathrm{M}\right)$ and by ODQ $\left(10^{-5} \mathrm{M}\right)$ (Fig. 5B). Inhibition of the sarcoplasmic reticulum ATPase (SERCA) with CPA $\left(2 \times 10^{-5} \mathrm{M}\right)$ had no effect on apelin-induced relaxation $\left(\mathrm{pD}_{2}=7.20 \pm 0.1\right.$ vs. $7.30 \pm$ $0.1 ; E_{\max }=48 \% \pm 6 \%$ vs. $48 \% \pm 4 \%$; in the absence and presence of CPA, respectively; $P>0.05, n=6$ ).

Apelin-Induced Relaxation of Coronary Arteries Requires BK $_{\mathbf{C a}}$ Channel Activation. In endotheliumintact coronary rings contracted with 5 -HT, blockade of large conductance, $\mathrm{BK}_{\mathrm{Ca}}$ channels with iberiotoxin $\left(10^{-7} \mathrm{M}\right)$ completely inhibited apelin-induced relaxation, whereas inhibition of ATP-sensitive $\mathrm{K}$ channels with glyburide $\left(10^{-6} \mathrm{M}\right)$ was without effect (Fig. 6A). Moreover, apelin failed to cause relaxation of rings contracted with a depolarizing concentration of potassium ions ( $40 \mathrm{mM}$ ) instead of 5-HT (Fig. 6B). The potassium-induced contractions were abolished by a voltagedependent calcium channel blocker, diltiazem $\left(10^{-5} \mathrm{M}\right)$, which caused $99 \% \pm 1 \%$ relaxation $(n=7)$.

The effect of $\mathrm{NO}$ on whole cell $\mathrm{BK}_{\mathrm{Ca}}$ currents was determined by using patch-clamp recording in freshly isolated coronary smooth muscle cells. $\mathrm{BK}_{\mathrm{Ca}}$ currents were increased in the presence of the NO donor, DEA NONOate $\left(10^{-5} \mathrm{M}\right)$ (Fig. 7, A-E). The DEA-induced increase in $\mathrm{BK}_{\mathrm{Ca}}$ current was blocked by iberiotoxin $\left(10^{-7} \mathrm{M}\right)$, whereas $\mathrm{ODQ}\left(10^{-5} \mathrm{M}\right)$ was without effect (Fig. 7, F and G). Similar results were obtained with $\operatorname{SNP}\left(10^{-5} \mathrm{M}\right)$ (data not shown).

\section{Discussion}

The primary goal of this study was to elucidate the mechanism(s) underlying apelin-induced dilation of coronary arteries. The results are the first to establish that apelin causes endothelium-dependent relaxation of isolated coronary arteries and that this response is due to activation of APJ receptors located on endothelial cells in the arterial wall, likely resulting in the release of NO. Notably, apelin-induced endotheliumdependent relaxation of coronary arteries is abolished by pharmacologic blockade of $\mathrm{BK}_{\mathrm{Ca}}$ channels and does not involve stimulation of the guanylyl cyclase/cGMP/PKG pathway. Taken together, these findings provide new insight into the signaling pathways by which apelin causes smooth muscle relaxation in coronary arteries.

It is generally held that apelin causes vasodilation in the peripheral circulation. Systemic administration of apelin decreases arterial blood pressure (Tatemoto et al., 2001; Ishida et al., 2004; Japp et al., 2010), and local infusion of the peptide increases blood flow (Japp et al., 2008, 2010). Based on their putative beneficial hemodynamic effects, apelin and apelin-like analogs are in clinical development for the treatment of several cardiovascular disorders, including heart failure and pulmonary hypertension (Brame et al., 2015; Narayanan et al., 2015; Yang et al., 2015). Surprisingly, there is little information regarding the effects of activating the apelin/APJ receptor system in specific vascular beds and the underlying molecular mechanisms that result in vascular smooth muscle relaxation, an understanding of which is critical for optimizing the safety and efficacy of such agents.

Vasodilators may exert their effects either by a direct action on vascular smooth muscle cells or by an indirect effect due to the release of relaxing factors, such as NO and prostacyclin, from endothelial cells in the blood vessel wall (O'Rourke et al., 2006). Several studies have demonstrated that the blood pressure-lowering and vasodilator effects of apelin are sensitive to inhibitors of endothelial nitric oxide synthase (eNOS) (Tatemoto et al., 2001; Ishida et al., 2004; Japp et al., 2008), 
A

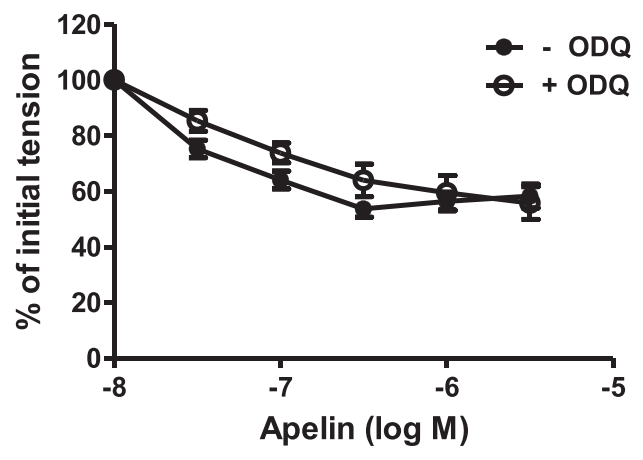

C

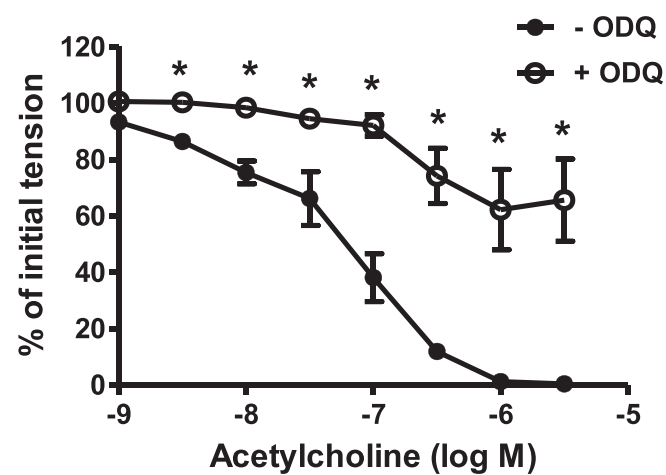

B

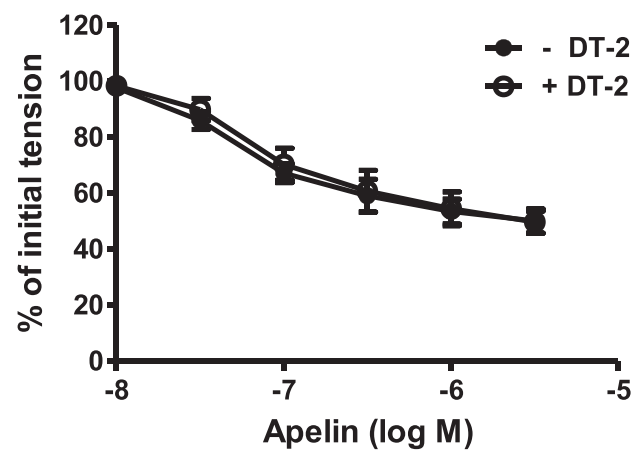

D

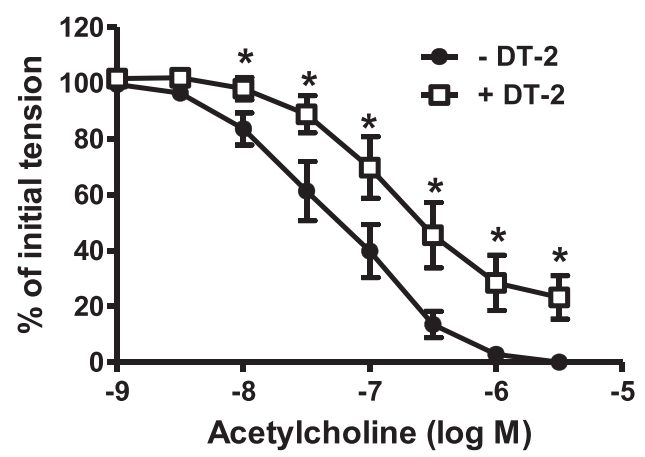

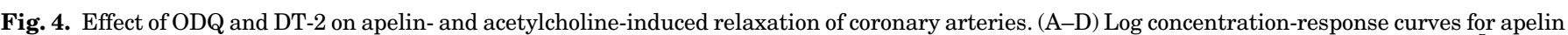

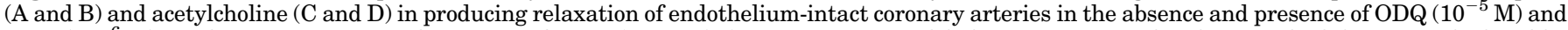

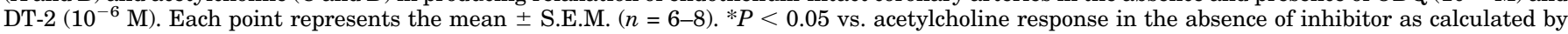
paired $t$ test.

suggesting a role for endothelial cell-derived NO; however, a limitation of in vivo studies such as these is that they do not identify a precise site of drug action. Studies with isolated blood vessels indicate that apelin may act via multiple mechanisms to cause vascular smooth muscle relaxation. Although apelin has been shown to activate eNOS in some vessels (Jia et al., 2007; Zhong et al., 2007), the human internal mammary artery is the only blood vessel studied thus far in which apelin-induced relaxation is completely eliminated by removal of the endothelium (Maguire et al., 2009). In these arteries, the endothelium-dependent response to apelin was insensitive to the eNOS inhibitor, $N$-nitro-Larginine methyl ester (L-NAME), but was abolished by inhibition of cyclooxygenase with indomethacin. In mouse aorta and rat portal vein, apelin causes both endotheliumdependent and endothelium-independent relaxations, with the endothelium-dependent component being at least partially sensitive to L-NAME (Gurzu et al., 2006; Wang et al., 2015). L-NAME also inhibits apelin-induced relaxation of human mesenteric arteries, whereas in hepatic arteries the response to apelin is unaffected by either L-NAME or the cyclooxygenase inhibitor, meclofenamate (Salcedo et al., 2007). Taken together, these studies indicate that apelin is capable of activating several mechanisms at the local level within the blood vessel wall to cause smooth muscle relaxation and vasodilation. These include stimulating the release of $\mathrm{NO}$ and vasodilator prostaglandins from endothelial cells, as well as a direct action on vascular smooth muscle cells.
In this study, apelin caused relaxation of isolated coronary arteries and this response was abolished by removal of the endothelium. These results suggest that, rather than acting directly on the coronary smooth muscle to cause relaxation, apelin exerts its effect via an action on endothelial cells. Molecular and imaging studies established that APJ receptors are expressed in coronary arteries and are indeed present on endothelial cells. Together with the observation that the APJ receptor antagonist, F13A, also abolished the response to apelin, the findings strongly support the notion that apelininduced relaxation of coronary arteries is due to activation of APJ receptors on the endothelial cells followed by the release of a vasorelaxant factor. Previous studies in isolated blood vessels indicate that endothelium-dependent relaxations evoked by apelin may be mediated by NO or by vasodilator prostaglandins (Gurzu et al., 2006; Salcedo et al., 2007; Maguire et al., 2009). Inhibition of cyclooxygenase with indomethacin had no effect on apelin-induced relaxation of coronary arteries, thereby ruling out prostaglandins in this response. Conversely, endothelium-dependent relaxation evoked by apelin was completely abolished by inhibition of eNOS with NLA, indicating that NO likely mediates apelininduced relaxation in coronary arteries. This conclusion is further supported by real-time imaging experiments demonstrating that apelin increased NO levels in isolated coronary endothelial cells, as measured by DAF-2 fluorescence. Moreover, the apelin-induced increase in intracellular NO was sensitive to inhibition by both NLA and F13A, as was observed 
A

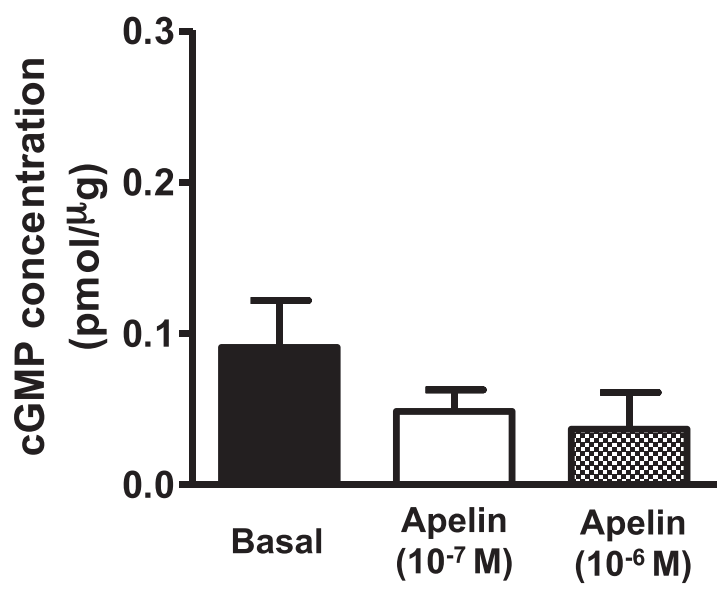

B

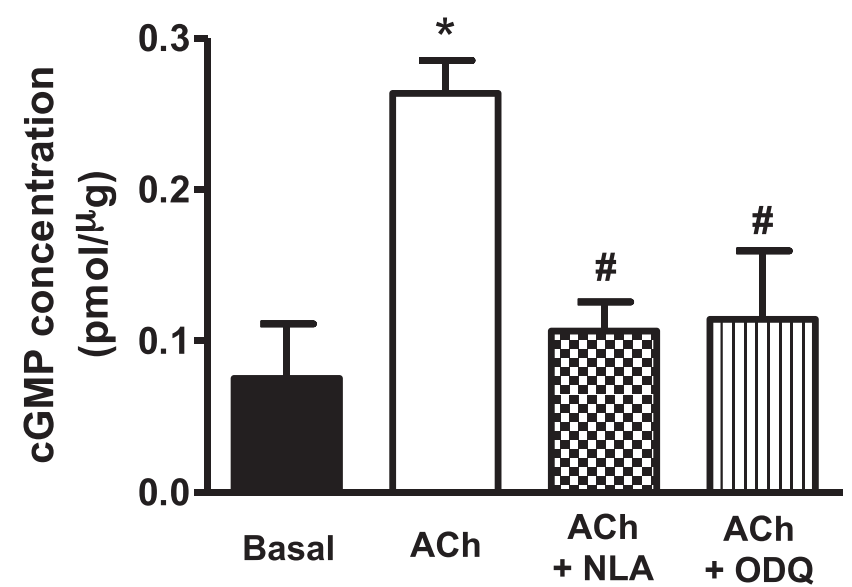

Fig. 5. Intracellular cGMP formation in response to apelin and acetylcholine in coronary arteries. (A and B) Bar graphs representing the effect of apelin $\left(10^{-7}\right.$ and $10^{-6} \mathrm{M}, 5$ minutes) (A) and acetylcholine $\left(10^{-6} \mathrm{M}\right.$, 5 minutes) (B) on intracellular cGMP levels in endothelium-intact coronary arterial segments. In addition, no change in cGMP levels was observed in coronary arteries incubated with apelin for up to 20 minutes (data not shown for the sake of clarity). Values are represented as means \pm S.E.M. $(n=3$ to 4$)$. ${ }^{*} P<0.05$ vs. basal; ${ }^{\#} P<0.05$ vs. acetylcholine alone as calculated by analysis of variance using the Tukey test as post hoc analysis. ACh, acetylcholine.

with the relaxation response to apelin in the functional studies.

It is well established that NO may cause relaxation of vascular smooth muscle via several mechanisms. NO increases the activity of guanylyl cyclase, resulting in an increase in intracellular cGMP levels and activation of PKG (Vanhoutte et al., 2016); however, NO may also act via cGMPindependent mechanisms, such as activation of $\mathrm{BK}_{\mathrm{Ca}}$ channels in the plasma membrane (Bolotina et al., 1994; Mistry and Garland, 1998) and activation of SERCA (Adachi et al., 2001). Although NO has been implicated in the vasodilator effects of apelin in some vascular beds, there have been no studies to date investigating the downstream signaling pathways by which NO released from endothelial cells in response to apelin causes vascular smooth muscle relaxation. The results of this study demonstrate that, in coronary arteries, apelin-induced relaxation occurs in a cGMP-independent manner, inasmuch

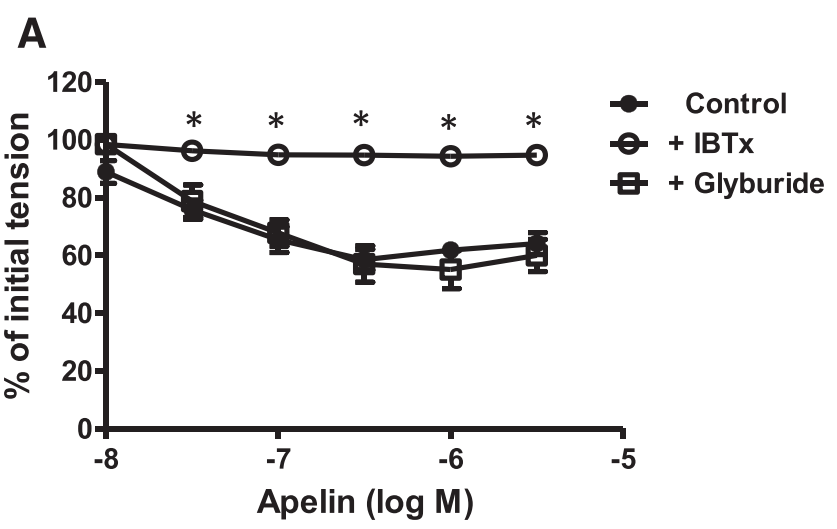

B

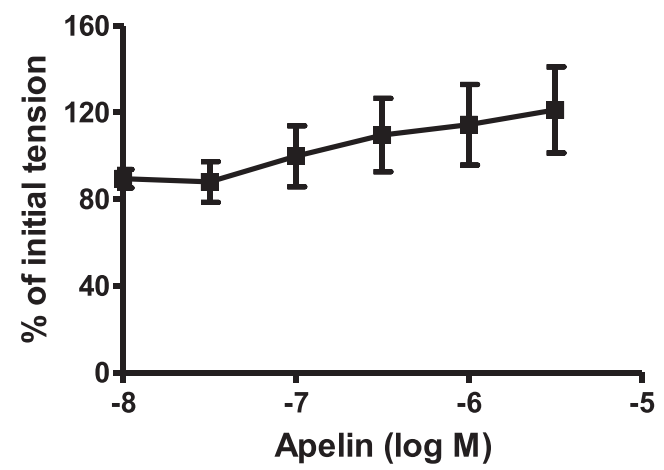

Fig. 6. Role of $\mathrm{K}$ channels in apelin-induced relaxation of coronary arteries. (A and B) Log concentration-response curves for apelin in producing relaxation of endothelium-intact coronary arteries: in the absence and presence of iberiotoxin $\left(10^{-7} \mathrm{M}, n=6\right)$ or glyburide $\left(10^{-6}\right.$ $\mathrm{M}, n=7$ ) (A) and arterial segments contracted with high potassium solution $\left(40 \mathrm{mM} \mathrm{K}^{+}, n=7\right)(\mathrm{B}) .{ }^{*} P<0.05$ vs. apelin alone as calculated by analysis of variance using the Tukey test as post hoc analysis. IBTx, iberiotoxin.

as apelin did not cause an increase in intracellular cGMP levels, nor was apelin-induced relaxation sensitive to inhibitors of guanylyl cyclase (i.e., ODQ) or PKG (i.e., DT-2). With regard to cGMP-independent mechanisms, a role for SERCA in the response to apelin in coronary arteries can be ruled out since apelin-induced relaxations were unchanged in the presence of CPA, a potent SERCA inhibitor (Seidler et al., 1989). Alternatively, several lines of evidence support the view that $\mathrm{NO}$ released in response to apelin causes activation of $\mathrm{BK}_{\mathrm{Ca}}$ channels to produce relaxation of coronary arteries. Apelininduced endothelium-dependent relaxation was abolished by iberiotoxin, a potent and selective $\mathrm{BK}_{\mathrm{Ca}}$ channel blocker (Galvez et al., 1990), whereas the ATP-sensitive K channel blocker, glyburide (Ashcroft and Ashcroft, 1990), was without effect. Moreover, K channel activators cause smooth muscle relaxation via mechanisms that are sensitive to membrane potential. Responses to such agents are eliminated by high concentrations of extracellular $\mathrm{K}^{+}$(Hamilton et al., 1986; Cook et al., 1988), which significantly attenuates or abolishes the driving force for $\mathrm{K}^{+}$efflux through membrane $\mathrm{K}$ channels. Indeed, apelin-induced relaxation was not observed in arteries contracted with a depolarizing concentration of $\mathrm{K}^{+}$, which is consistent with a mechanism of action that is susceptible to changes in membrane potential. NO-induced activation of 
A

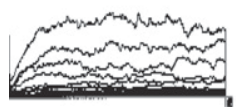

Control
B

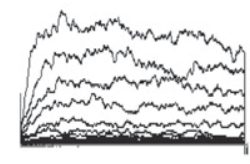

DEA
C

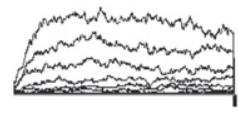

Control
D

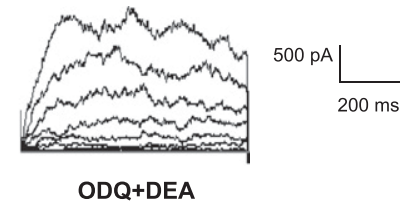

\section{G}

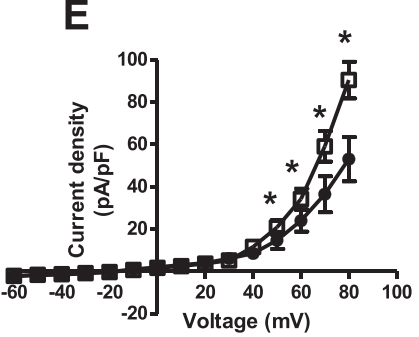

F
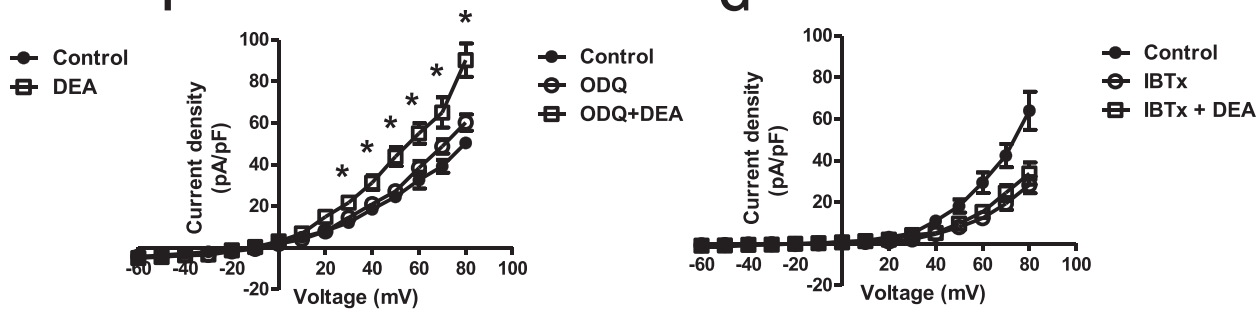

Fig. 7. Effect of DEA NONOate, in the absence and presence of ODQ or iberiotoxin, on whole cell $\mathrm{BK}_{\mathrm{Ca}}$ currents in isolated coronary smooth muscle cells. Whole cell $\mathrm{BK}_{\mathrm{Ca}}$ currents were recorded in freshly isolated vascular smooth muscle cells in response to successive voltage pulses of 800-millisecond duration, increasing in $10-\mathrm{mV}$ increments from -60 to $+80 \mathrm{mV}$ before and after treatment with DEA NONOate $\left(10^{-5} \mathrm{M}\right)$ with and without ODQ $\left(10^{-5} \mathrm{M}\right)$ or iberiotoxin $\left(10^{-7} \mathrm{M}\right)$. (A-D) Representative tracings depicting the sequential current recordings from a single smooth muscle cell before (A and C) and after treatment with DEA $\left(10^{-5} \mathrm{M}, 2\right.$ minutes) alone (B) or with ODQ $\left(10^{-5} \mathrm{M}, 5\right.$ minutes) plus DEA (10 ${ }^{-5} \mathrm{M}, 2$ minutes) (D). (E-G) Summary I-V curve plots of $\mathrm{BK}_{\mathrm{Ca}}$ currents at baseline and after treatment with DEA $\left(10^{-5} \mathrm{M}\right)$, in the absence (E) and presence $(\mathrm{F})$ of ODQ $\left(10^{-5} \mathrm{M}\right)$ or $(\mathrm{G})$ iberiotoxin $\left(10^{-7}\right.$ $\mathrm{M})$. Values are presented as the mean \pm S.E.M. $(n=6) . * P<0.05$ vs. control current density. DEA, DEA NONOate; IBTx, iberiotoxin.

$\mathrm{BK}_{\mathrm{Ca}}$ channels in coronary vascular smooth muscle cells was confirmed in patch-clamp recording experiments, in which $\mathrm{BK}_{\mathrm{Ca}}$ currents were increased in the presence of two different NO donors, DEA and SNP. That ODQ had no effect on the NO-induced increase in $\mathrm{BK}_{\mathrm{Ca}}$ channel activation is in agreement with the lack of effect of guanylyl cyclase inhibition on the functional response to apelin and supports the notion that NO can activate $\mathrm{BK}_{\mathrm{Ca}}$ channels in a cGMP-independent manner (Bolotina et al., 1994; Mistry and Garland, 1998).

The results of this study provide a mechanistic basis for the increase in coronary blood flow that is observed after intracoronary infusion of apelin (Japp et al., 2010). By stimulating endothelial APJ receptors and releasing NO, which in turn activates $\mathrm{BK}_{\mathrm{Ca}}$ channels in the underlying smooth muscle cells, apelin causes endothelium-dependent relaxation of coronary arteries, thereby leading to vasodilation. Moreover, this response to apelin-induced NO release occurs independently of any change in intracellular cGMP levels. By contrast, endothelium-dependent relaxation to acetylcholine was associated with increased cGMP formation. Although somewhat speculative at present, these differences in signaling mechanisms (i.e., $\mathrm{BK}_{\mathrm{Ca}}$ channel-dependent versus cGMPdependent) could help to explain, at least in part, why apelin-induced vasodilation is preserved in patients with heart failure (Japp et al., 2010; Barnes et al., 2013), whereas responses to acetylcholine are impaired (Treasure et al., 1990; Kubo et al., 1991; Bitar et al., 2006). These observations notwithstanding, it is important to recognize that the experiments were conducted on animal tissues and cells, which is a limitation of this study. Similar studies with human coronary arteries will be essential to establish whether the current findings in coronary arteries of the rat will translate to human arteries. A second caveat is that $\mathrm{BK}_{\mathrm{Ca}}$ channel expression and function are reduced in certain cardiovascular diseases such as hypertension and diabetes (Amberg and Santana, 2003; Dong et al., 2008; Yang et al., 2013; Nieves-Cintrón et al.,
2017). If such changes were to occur in the coronary circulation of patients with heart disease(s), the potential therapeutic benefit of apelin to improve cardiac perfusion could be limited by the reduced number of functional $\mathrm{BK}_{\mathrm{Ca}}$ channels in coronary smooth muscle cells that are available for activation by NO released in response to apelin. Future studies aimed at addressing these questions and improving our understanding of the apelin/APJ receptor-signaling pathways that elicit vasodilation may provide guidance for the development of novel apelin-like therapeutic agents.

\section{Authorship Contributions}

Participated in research design: Mughal, Sun, O'Rourke.

Conducted experiments: Mughal.

Performed data analysis: Mughal, Sun, O’Rourke.

Wrote or contributed to the writing of the manuscript: Mughal, O'Rourke.

\section{References}

Adachi T, Matsui R, Weisbrod RM, Najibi S, and Cohen RA (2001) Reduced sarco/endoplasmic reticulum $\mathrm{Ca}(2+)$ uptake activity can account for the reduced response to NO, but not sodium nitroprusside, in hypercholesterolemic rabbit aorta. Circulation 104:1040-1045.

Amberg GC and Santana LF (2003) Downregulation of the BK channel beta1 subunit in genetic hypertension. Circ Res 93:965-971.

Ashcroft SJ and Ashcroft FM (1990) Properties and functions of ATP-sensitive K-channels. Cell Signal 2:197-214.

Barnes GD, Alam S, Carter G, Pedersen CM, Lee KM, Hubbard TJ, Veitch S, Jeong H, White A, Cruden NL, et al. (2013) Sustained cardiovascular actions of APJ agonism during renin-angiotensin system activation and in patients with heart failure. Circ Heart Fail 6:482-491.

Bitar F, Lerman A, Akhter MW, Hatamizadeh P, Janmohamed M, Khan S, and Elkayam U (2006) Variable response of conductance and resistance coronary arteries to endothelial stimulation in patients with heart failure due to nonischemic dilated cardiomyopathy. J Cardiovasc Pharmacol Ther 11:197-202.

Bolotina VM, Najibi S, Palacino JJ, Pagano PJ, and Cohen RA (1994) Nitric oxide directly activates calcium-dependent potassium channels in vascular smooth muscle. Nature 368:850-853.

Boucher J, Masri B, Daviaud D, Gesta S, Guigné C, Mazzucotelli A, Castan-Laurell I, Tack I, Knibiehler B, Carpéné C, et al. (2005) Apelin, a newly identified adipokine up-regulated by insulin and obesity. Endocrinology 146:1764-1771.

Brame AL, Maguire JJ, Yang P, Dyson A, Torella R, Cheriyan J, Singer M, Glen RC, Wilkinson IB, and Davenport AP (2015) Design, characterization, and first-inhuman study of the vascular actions of a novel biased apelin receptor agonist. Hypertension 65:834-840. 
Cook NS, Weir SW, and Danzeisen MC (1988) Anti-vasoconstrictor effects of the K+ channel opener cromakalim on the rabbit aorta-comparison with the calcium antagonist isradipine. $\mathrm{Br} J$ Pharmacol 95:741-752.

Dong L, Zheng YM, Van Riper D, Rathore R, Liu QH, Singer HA, and Wang YX (2008) Functional and molecular evidence for impairment of calcium-activated potassium channels in type-1 diabetic cerebral artery smooth muscle cells. $J$ Cereb Blood Flow Metab 28:377-386.

Galvez A, Gimenez-Gallego G, Reuben JP, Roy-Contancin L, Feigenbaum P, Kaczorowski GJ, and Garcia ML (1990) Purification and characterization of a unique potent, peptidyl probe for the high conductance calcium-activated potassium channel from venom of the scorpion Buthus tamulus. J Biol Chem 265: $11083-11090$.

Golino P, Piscione F, Benedict CR, Anderson HV, Cappelli-Bigazzi M, Indolfi C, Condorelli M, Chiariello M, and Willerson JT (1994) Local effect of serotonin released during coronary angioplasty. $N$ Engl J Med 330:523-528.

Gonzales AL, Amberg GC, and Earley S (2010) Ca2+ release from the sarcoplasmic reticulum is required for sustained TRPM4 activity in cerebral artery smooth muscle cells. Am J Physiol Cell Physiol 299:C279-C288.

Gurzu B, Petrescu BC, Costuleanu M, and Petrescu G (2006) Interactions between apelin and angiotensin II on rat portal vein. J Renin Angiotensin Aldosterone Syst 7:212-216.

Hamilton TC, Weir SW, and Weston AH (1986) Comparison of the effects of BRL 34915 and verapamil on electrical and mechanical activity in rat portal vein. $\mathrm{Br} J$ Pharmacol 88:103-111.

Han X, Zhang DL, Yin DX, Zhang QD, and Liu WH (2013) Apelin-13 deteriorates hypertension in rats after damage of the vascular endothelium by ADMA. Can $J$ Physiol Pharmacol 91:708-714.

Hosoya M, Kawamata Y, Fukusumi S, Fujii R, Habata Y, Hinuma S, Kitada C, Honda S, Kurokawa T, Onda H, et al. (2000) Molecular and functional characteristics of APJ. Tissue distribution of mRNA and interaction with the endogenous ligand apelin. J Biol Chem 275:21061-21067.

Houston DS, Shepherd JT, and Vanhoutte PM (1986) Aggregating human platelets cause direct contraction and endothelium-dependent relaxation of isolated canine coronary arteries. Role of serotonin, thromboxane A2, and adenine nucleotides. $J$ Clin Invest 78:539-544.

Ishida J, Hashimoto T, Hashimoto Y, Nishiwaki S, Iguchi T, Harada S, Sugaya T, Matsuzaki H, Yamamoto R, Shiota N, et al. (2004) Regulatory roles for APJ, a seven-transmembrane receptor related to angiotensin-type 1 receptor in blood pressure in vivo. J Biol Chem 279:26274-26279.

Japp AG, Cruden NL, Amer DA, Li VK, Goudie EB, Johnston NR, Sharma S, Neilson I, Webb DJ, Megson IL, et al. (2008) Vascular effects of apelin in vivo in man. $J A m$ Coll Cardiol 52:908-913.

Japp AG, Cruden NL, Barnes G, van Gemeren N, Mathews J, Adamson J, Johnston NR, Denvir MA, Megson IL, Flapan AD, et al. (2010) Acute cardiovascular effects of apelin in humans: potential role in patients with chronic heart failure. Circulation 121:1818-1827.

Jia YX, Lu ZF, Zhang J, Pan CS, Yang JH, Zhao J, Yu F, Duan XH, Tang CS, and Qi YF (2007) Apelin activates L-arginine/nitric oxide synthase/nitric oxide pathway in rat aortas. Peptides 28:2023-2029.

Kleinbongard P, Böse D, Baars T, Möhlenkamp S, Konorza T, Schöner S, ElterSchulz M, Eggebrecht H, Degen H, Haude M, et al. (2011) Vasoconstrictor potential of coronary aspirate from patients undergoing stenting of saphenous vein aortocoronary bypass grafts and its pharmacological attenuation. Circ Res 108:344-352

Kleinz MJ and Davenport AP (2004) Immunocytochemical localization of the endogenous vasoactive peptide apelin to human vascular and endocardial endothelial cells. Regul Pept 118:119-125.

Kleinz MJ, Skepper JN, and Davenport AP (2005) Immunocytochemical localisation of the apelin receptor, APJ, to human cardiomyocytes, vascular smooth muscle and endothelial cells. Regul Pept 126:233-240.

Kubo SH, Rector TS, Bank AJ, Williams RE, and Heifetz SM (1991) Endotheliumdependent vasodilation is attenuated in patients with heart failure. Circulation $\mathbf{8 4}$ $1589-1596$.

Lee DK, Saldivia VR, Nguyen T, Cheng R, George SR, and O'Dowd BF (2005) Modification of the terminal residue of apelin-13 antagonizes its hypotensive action Endocrinology 146:231-236.

Li J, Zhang H, and Zhang C (2012) Role of inflammation in the regulation of coronary blood flow in ischemia and reperfusion: mechanisms and therapeutic implications. J Mol Cell Cardiol 52:865-872.

Maguire JJ, Kleinz MJ, Pitkin SL, and Davenport AP (2009) [Pyr1]apelin-13 identified as the predominant apelin isoform in the human heart: vasoactive mechanisms and inotropic action in disease. Hypertension 54:598-604.
Mistry DK and Garland CJ (1998) Nitric oxide (NO)-induced activation of large conductance $\mathrm{Ca} 2+$-dependent $\mathrm{K}+$ channels $(\mathrm{BK}(\mathrm{Ca})$ ) in smooth muscle cells isolated from the rat mesenteric artery. $B r J$ Pharmacol 124:1131-1140.

Modgil A, Guo L, O'Rourke ST, and Sun C (2013) Apelin-13 inhibits largeconductance $\mathrm{Ca} 2+$-activated $\mathrm{K}+$ channels in cerebral artery smooth muscle cells via a PI3-kinase dependent mechanism. PLoS One 8:e83051.

Narayanan S, Harris DL, Maitra R, and Runyon SP (2015) Regulation of the apelinergic system and its potential in cardiovascular disease: peptides and small molecules as tools for discovery. J Med Chem 58:7913-7927.

Nieves-Cintrón M, Syed AU, Buonarati OR, Rigor RR, Nystoriak MA, Ghosh D, Sasse KC, Ward SM, Santana LF, Hell JW, et al. (2017) Impaired $\mathrm{BK}_{\mathrm{Ca}}$ channel function in native vascular smooth muscle from humans with type 2 diabetes. Sci Rep 7: 14058

O'Carroll AM, Lolait SJ, Harris LE, and Pope GR (2013) The apelin receptor APJ: journey from an orphan to a multifaceted regulator of homeostasis. J Endocrinol 219:R13-R35.

O'Rourke ST, Vanhoutte PM, and Miller VM (2006) Biology of blood vessels: vascular pharmacology, in Vascular Medicine (Creager MA, Loscalzo J, and Dzau VJ eds) pp 71-100, Saunders/Elsevier Publishers, Philadelphia

Pitkin SL, Maguire JJ, Kuc RE, and Davenport AP (2010) Modulation of the apelin/ APJ system in heart failure and atherosclerosis in man. $B r J$ Pharmacol 160: 1785-1795.

Reaux A, Gallatz K, Palkovits M, and Llorens-Cortes C (2002) Distribution of apelinsynthesizing neurons in the adult rat brain. Neuroscience 113:653-662.

Salcedo A, Garijo J, Monge L, Fernández N, Luis García-Villalón A, Sánchez Turrión V, Cuervas-Mons V, and Diéguez G (2007) Apelin effects in human splanchnic arteries. Role of nitric oxide and prostanoids. Regul Pept 144:50-55

Seidler NW, Jona I, Vegh M, and Martonosi A (1989) Cyclopiazonic acid is a specific inhibitor of the $\mathrm{Ca} 2+-\mathrm{ATP} a \mathrm{se}$ of sarcoplasmic reticulum. $J$ Biol Chem 264: 17816-17823.

Sonkusare SK, Bonev AD, Ledoux J, Liedtke W, Kotlikoff MI, Heppner TJ, HillEubanks DC, and Nelson MT (2012) Elementary Ca2+ signals through endothelia TRPV4 channels regulate vascular function. Science 336:597-601.

Tatemoto K, Hosoya M, Habata Y, Fujii R, Kakegawa T, Zou MX, Kawamata Y, Fukusumi S, Hinuma S, Kitada C, et al. (1998) Isolation and characterization of a novel endogenous peptide ligand for the human APJ receptor. Biochem Biophys Res Commun 251:471-476.

Tatemoto K, Takayama K, Zou MX, Kumaki I, Zhang W, Kumano K, and Fujimiya M (2001) The novel peptide apelin lowers blood pressure via a nitric oxide-dependent mechanism. Regul Pept 99:87-92.

Treasure CB, Vita JA, Cox DA, Fish RD, Gordon JB, Mudge GH, Colucci WS, Sutton MG, Selwyn AP, Alexander RW, et al. (1990) Endothelium-dependent dilation of the coronary microvasculature is impaired in dilated cardiomyopathy. Circulation 81:772-779.

Tunstall RR, Shukla P, Grazul-Bilska A, Sun C, and O'Rourke ST (2011) MT2 receptors mediate the inhibitory effects of melatonin on nitric oxide-induced relaxation of porcine isolated coronary arteries. J Pharmacol Exp Ther 336:127-133.

Vanhoutte PM, Zhao Y, Xu A, and Leung SW (2016) Thirty years of saying NO: sources, fate, actions, and misfortunes of the endothelium-derived vasodilator mediator. Circ Res 119:375-396.

Wang Z, Yu D, Wang M, Wang Q, Kouznetsova J, Yang R, Qian K, Wu W, Shuldiner A, Sztalryd C, et al. (2015) Elabela-apelin receptor signaling pathway is functional in mammalian systems. Sci Rep 5:8170.

Yang P, Maguire JJ, and Davenport AP (2015) Apelin, Elabela/Toddler, and biased agonists as novel therapeutic agents in the cardiovascular system. Trends Pharmacol Sci 36:560-567.

Yang Y, Li PY, Cheng J, Mao L, Wen J, Tan XQ, Liu ZF, and Zeng XR (2013) Function of BKCa channels is reduced in human vascular smooth muscle cells from Han Chinese patients with hypertension. Hypertension 61:519-525.

Zhang Q, Yao F, Raizada MK, O'Rourke ST, and Sun C (2009) Apelin gene transfer into the rostral ventrolateral medulla induces chronic blood pressure elevation in normotensive rats. Circ Res 104:1421-1428.

Zhong JC, Yu XY, Huang Y, Yung LM, Lau CW, and Lin SG (2007) Apelin modulates aortic vascular tone via endothelial nitric oxide synthase phosphorylation pathway in diabetic mice. Cardiovasc Res 74:388-395.

Address correspondence to: Dr. Stephen T. O'Rourke, Department of Pharmaceutical Sciences, North Dakota State University, Fargo, ND 581086050. E-mail: stephen.orourke@ndsu.edu 